\title{
Rhetorical Representations of Masculinities in South Africa: Moving Towards a Material-Discursive Understanding of Men
}

\author{
RUSSELL LUYT \\ The London School of Economics and Political Science, London, UK
}

\begin{abstract}
A material-discursive perspective holds advantage in understanding male realities. It seeks to integrate dominant approaches that appear anaemic in their failure to capture the interplay between the material and discursive realms of human existence. Three dominant metaphorical themes in the rhetorical representation of South African masculinities are described in an attempt to illustrate the complexity of embodied masculine experience. In this sense the discussion seeks to reveal the dynamic nature of masculine debate and lived experience across differing contexts. It serves to underline the importance of adopting a material-discursive perspective in understanding men, which recognizes that they do not exist as a homogeneous social group, and as such experience their masculinities in a variable and changing fashion. The theoretical amalgamation of social representations and rhetoric is argued to provide a useful analytical tool in an endeavour of this nature. It is suggested that the rhetorical approach problematizes an overly consensual view of social reality that social representations theory typically promotes.
\end{abstract}

Key words: masculinity; material-discursive perspective; rhetorical representations; men; South Africa

\section{INTRODUCTION}

The current article argues that a material-discursive perspective holds advantage in understanding male realities. Although this perspective is well established (e.g. Berndtson, 1960; Ray \& Shaw, 1987; Szwed, 1975), it has found increasing favour not only in masculinity research (e.g. Kehily, 2001; Mangan, 1999; Messerschmidt, 1999; Roberts, 2002; Sparks \& Smith, 2002), but across traditional disciplinary divides (e.g. Hörschelmann, 2001; Kim, 2001; Radley, 1997; Taylor, 2001). In essence it is recognized that human experience necessarily emerges through the interplay between both material and discursive reality. Three dominant metaphorical themes in the rhetorical representation of South African masculinities are described later. This highlights the worth of adopting a materialdiscursive perspective in understanding the complexity of male experience. Participant debate reveals its dynamic and context-bound nature. Far from existing as a homogenous social group men experience their gender in complex and contradictory ways. It is suggested that the theoretical integration of social representations and rhetoric provides a useful analytical tool in this endeavour.

At the outset it is worth noting that the argument presented here often makes use of rigid 
theoretical distinctions. The informed reader may find this lack of subtlety overly simplistic. However given the brevity of, what is essentially an empirical article, it is felt that this frailty may find legitimate sanctuary. Where possible the reader is directed to texts that cover these issues with greater finesse.

The first of numerous stark, but conceptually useful comparisons exists between 'psychological' and 'sociological' theoretical explanation. In essence this difference reflects a fundamental deviation in the level of analysis each approach adopts (Wetherell \& Griffin, 1991). Social psychology straddles this divide, where a gulf persists between these two explanatory models, rendering at times an integrated approach problematic. This gulf is considered conceptually false. No single model is seen to provide holistic understanding, and consequently, their combined consideration is believed to be of the utmost worth (Foster, 1997). The material-discursive perspective exists as one, among many trends (social representations providing a good theoretical example), that aims to bridge this divide.

For the purpose of this discussion it is useful to define the two broad approaches to understanding individual reality from which the material-discursive perspective emanates. These may be described as the material-naturalistic ('psychological') and discursiveconstructionist ('sociological') outlook (Nettleton, 2000; Yardley, 1997). Alone they fail to capture the interplay between the material and discursive realms of human existence.

Quintessentially the material-naturalistic approach reflects Enlightenment thought. It is claimed that all experience may be explained in terms of the observable physical world, including the body and the surrounding environment, these operating independently of each other (Nettleton, 2000; Yardley, 1997). This approach, which in essence separates the body from the social and material worlds, denies subjectivity of experience. Feminism, in particular, has emphasized the overly deterministic nature that this bounded and static portrayal of reality suggests. It is claimed that this has merely served to justify inequality between men and women-supposedly resting on their innately different (and hence unchanging) physiological capabilities (Nettleton, 2000).

In antithesis the discursive-constructionist approach may be characterized by its postmodern outlook. It stresses the socio-linguistically shaped nature of human experience, in its extreme form, suggesting that bodies and objects merely reflect the discourses that describe them (Yardley, 1997). That is to say the body is seen to exist as a tabula rasa, upon which social text is written, having taken form within pre-existing discourses of power. It is argued that through the physical performance of these texts, bodies are materialized and thus thought to be real, rather than due to any essential individuality (Burkitt, 1999). As such this approach is scathing of material-naturalistic explanation that purportedly fails to acknowledge human subjective experience in its dogmatic claim to objective physical reality. This, crucially, neglects to account for the reproduction of discursive meaning within structural relations of power (Yardley, 1997).

This approach has failed to garner widespread support within mainstream psychology. Its critique surrounding many of the discipline's core principles, as well as its neglect to account for the materiality of human life (through privileging socio-linguistic reality) 
continues to render it marginal (Yardley, 1997). Specifically this outlook flounders when encountering individual challenge to normative practice. That is to say it clearly favours overarching structural influence in its description of human experience, to the detriment of individual agency, which presumably lurks unseen behind prevailing societal discourse. In short the discursive-constructionist approach highlights the body's existence, as a textual 'product', but largely disregards its role as an active 'producer' (Burkitt, 1999).

Thus the material-naturalistic and discursive-constructionist perspectives alone contribute only a partial understanding of human experience. Each exhibits reductionist tendencies, evident in either a neglect of the discursive or material dimension of reality (Yardley, 1997). It is suggested that the relatively new 'sociology of the body', or alternatively 'embodied sociology', provides a plausible point of departure toward the integration of these approaches (Nettleton, 2000; Williams \& Bendelow, 1998). Whilst the 'sociology of the body' stresses its importance as an object of sociological study, 'embodied sociology' positions it beyond this conventional objectivism, in which the phenomenological gains precedence (Williams \& Bendelow, 1998). The latter approach is adopted here in which the body is considered to be both discursively and materially reproduced.

This article therefore stresses that bodily processes, emotions, cognitions, and social relations are intricately intertwined (Carpenter, 2000). It is through this lived body that an account of both discursive and material reality may be achieved. This explanation takes due cognisance of structured social relations, whilst at the same time acknowledging the potentiality for active individual agency (Burkitt, 1999) within the dynamism of changing social and historical contexts (Watson, 2000). Crucially an account of the lived body underscores the importance of intentionality, in which the body exists not as a passive object or mere discursive entity, but as an active agent (Nettleton, 2000; Radley, 1997).

Clearly the material-naturalistic ('psychological') and discursive-constructionist ('sociological') perspectives appear anaemic in their failure to capture the interplay between the material and discursive realms of human existence. An 'embodied sociology' lays a new path in understanding human experience as both a material and discursive artifact. In short it is useful to view the 'body as a project' that 'may be best conceptualized as an unfinished biological and social phenomenon, which is transformed, within changing limits, as a result of its participation in society' (Nettleton, 2000, p. 109). A materialdiscursive perspective therefore seems not only useful, but also essential, to any inclusive understanding of human experience. Importantly it contributes toward our understanding of gender.

Unitary explanations of gender found early support, positing the existence of two monolithic categories: ‘the Male' and 'the Female'. Dominant amongst these, sex role theorizing suggests that a socially predetermined number of appropriate 'sex roles' are assigned to individuals according to their biological sex. Consequent acquiescence to gender suitable behaviour is seen to occur in response to normative expectation, which if unmet, leads to negative social sanction (Brittan, 1989; Connell, 1987). The theory provides a useful plateau from which to view gender, '... account(ing) for the apparent "spontaneity" and "naturalness" of gender, and do(ing) so in terms of a familiar appeal to structures and processes...' (Coleman, 1990, p. 192). Nevertheless grave flaws appear within the theory specifically, and the approach more generally, that undermines its utility as a means with which to explore masculinity (Brittan, 1989; Connell, 1987; West \& Zimmerman, 
This is the peer reviewed version of the following article: Luyt, Russell (2003) Rhetorical representations of masculinities in South Africa: Moving towards a material-discursive understanding of men. Journal of Community \& Applied Social Psychology, 13 (1). pp. 46-69. ISSN 1052-9284 (Print), 1099-1298 (Online) (doi:10.1002/casp.706), which has been published in final form at http://doi.org/10.1002/casp.706. This article may be used for non-commercial purposes in accordance with Wiley Terms and Conditions for Self-Archiving.

1991; Wetherall \& Griffin, 1991). Connell (1993) notes that despite the theory's popular appeal it is ultimately reductionist in its explanation of gender as an underlying individual psychological quality; this seen to govern human behaviour that is either unyieldingly 
masculine or feminine. Thus despite a concerted, and admirable attempt to break free from the confines of material-naturalism, the theory's foundational principles of individualism continue to anchor it within this perspective. This neglect to account for heterogeneity in masculine understanding ' . . has tended to produce an image of men that is white, middle class and heterosexual' (Frank, 1987); one might also add Western.

Usefully Watson (2000, p. 142) asserts that the conventional analysis of men as a unitary social category disregards their differential location in broader relations of social and economic power, and as such has rendered masculinity a 'poorly understood and inadequately operationalized' concept. Carpenter (2000) argues that Bob Connell's theorizing of masculinity provides a useful base on which an exploration of masculine experience may be built. In recognition that social life gains coherence through individual membership within fluid social categories (Thapan, 1997), his theoretical framework stresses the importance of changing masculine understanding across social divisions such as 'race', sexuality and class (Carpenter, 2000). It is claimed that in order to account for masculine difference in a worthwhile fashion, unitary concepts need to be abandoned, and analysis ought to venture beyond the individualist realm to incorporate socio-historical influence (Frank, 1987). The concept of 'doing masculinity' achieves this, viewing gender as a negotiated social category, existing between individuals through interaction.

No longer is gender understood as located within each individual as an essence, but rather finds constant reproduction through socially informed behavioural interaction, which allow men and women to continually affirm their membership to suitable sex categories (Frank, 1987; West \& Zimmerman, 1991). Acquiescence to normative gender demand meets with social reward whilst failure to do so results in negative social sanction (West \& Zimmerman, 1991). Normative gendered behaviours vary across context, are acted-out in multiple arenas, and find unique definition as a result of their specific cultural and ideological location in time (Connell, 1995).

Notwithstanding the immense variability in the manifestation of normative gendered behaviour across socio-historical context, it reliably suggests particular power relations (Carrigan, Connell, \& Lee, 1987), based on the universal principle of male dominance over women (Connell, 1987; Hearn \& Collinson, 1994). It is argued that whilst cultural ideals of masculinity may vary substantially, they do so in a fashion that consistently maintains existing relations of masculine domination, congruent with the peculiarities of the surrounding social structure (Connell, 1987). This cultural ideal is well described by the concept of hegemonic masculinity that serves to sustain male power, both in relation to women and with respect to subordinate masculinities, encouraging most men to support its perpetuation despite their frequent departure from its idealized form (Connell, 1987; Pyke, 1996). However hegemonic masculinity's supremacy does not suggest its total dominance, in which social differences along 'race', class and sexuality often act as catalysts for contestation over its meaning (Hearn \& Collinson, 1994). Carrigan et al. (1987, p. 98) usefully contribute: 'Hegemonic masculinity might be seen as what would function automatically if the strategy were entirely successful'.

Connell's theorizing has been criticized from various quarters (Demetriou, 2001; Jefferson, 2002; Speer, 2001; Wetherell \& Edley, 1999; Whitehead, 1999), specifically for its reification of masculine experience through its emphasis on the structuring effects of social categories such as 'race', class and sexuality. This is said (once again) to reduce 
This is the peer reviewed version of the following article: Luyt, Russell (2003) Rhetorical representations of masculinities in South Africa: Moving towards a material-discursive understanding of men. Journal of Community \& Applied Social Psychology, 13 (1). pp. 46-69. ISSN 1052-9284 (Print), 1099-1298 (Online) (doi:10.1002/casp.706), which has been published in final form at http://doi.org/10.1002/casp.706. This article may be used for non-commercial purposes in accordance with Wiley Terms and Conditions for Self-Archiving.

the complexity of individual male experience. Despite this inevitable over-simplification his theoretical scaffold is nonetheless believed to offer a useful point of entry into the wilderness of societal masculine negotiation (Carpenter, 2000). The theory implicitly operates 
from within a material-discursive orientation, and as such concedes that masculine ideology may only be experienced through the body (Burkitt, 1999).

Increasingly empirical initiatives have sought to actualize embodied analyses of masculinity, more often than not, implicitly from within this theoretical school. Campbell (2001), for example, explores the socio-environmental context in which most 'Black' South African mineworkers are forced to live. Men in this context are seen to adopt an adaptive masculinity that aids their ability to cope in physically dangerous and emotionally isolated settings. In particular this incorporates notions of a socially prescribed male 'hyper-sexuality', which together with low levels of self-efficacy (experienced as a result of poor and unpredictable working conditions), spurs the likelihood of multiple unprotected sexual encounters. In effect these studies illustrate that gender exists as a complex of symbolic material representations made possible through the body (Watson, 2000).

\section{EXPLORING MATERIAL-DISCURSIVE REALITY: INTEGRATING SOCIAL REPRESENTATIONS AND RHETORICAL THEORY}

Billig (1988, 1993) eloquently explores the worth of incorporating a rhetorical perspective within the theory of social representations. This article supports their amalgamation in the exploration of material-discursive reality, particularly masculine embodied experience, so as to account for its dynamic negotiation and practice within society. In agreement with the two central tenets of social representations, rhetoric likewise stresses the social nature of thinking, as well as the importance of thinking in social life. However, the rhetorical perspective problematizes an overly consensual view of social reality that social representations espouses, in its stress on the dialogic nature of thought. This emphasis is considered crucial in any exploration of masculinities that are necessarily embedded within contexts of contested meaning. This brief overview will not attempt to provide a definitive account surrounding the integration of social representations and rhetoric, this already dexterously undertaken by Billig (1988, 1993), but rather highlight its merit for future materialdiscursive analyses of masculinity.

Recently the inexhaustible author Michael Billig (1985, 1991, 1993, 1996, 1997) has spurred a revival of interest in rhetoric. Grounded within the wider critical movement (Billig, 1997), rhetoric finds itself in naked opposition to many core doctrines embraced by mainstream social psychology, preferably dismissing the 'absolute order' of dominant theorizing as overly restrictive in our (claimed) current era of post-modern contradiction and confusion (Billig, 1991, 1996). In particular, cognitive psychology exists in decided antithesis to the rhetorical perspective in its explanation of human thinking.

Drawing on modernist philosophy, cognitivism conceives of thinking as an individual problem-solving exercise, achieved by means of predetermined internalized rules that act to guide individual interpretation of surrounding stimuli (Billig, 1991, 1993). Alternatively Billig (1991) suggests that thinking is better captured through the notion of 'rule-questioning', which effectively de-centres thought processes from within 'individual heads', and relocates them in an unstable social milieu characterized by argumentation. From this standpoint thinking finds root in matters of public debate, wherein individual attitudes ' ... refer not just to the beliefs we might uphold, but refer to those other positions in a public argument 
This is the peer reviewed version of the following article: Luyt, Russell (2003) Rhetorical representations of masculinities in South Africa: Moving towards a material-discursive understanding of men. Journal of Community \& Applied Social Psychology, 13 (1). pp. 46-69. ISSN 1052-9284 (Print), 1099-1298 (Online) (doi:10.1002/casp.706), which has been published in final form at http://doi.org/10.1002/casp.706. This article may be used for non-commercial purposes in accordance with Wiley Terms and Conditions for Self-Archiving.

to which we are opposed' (Billig, 1991, p. 43). In so doing the concept of rhetoric accounts for both the shared and non-shared aspects of attitudes, aiding an attempt to integrate social and individualist traditions, in which any two debaters are concurrently seen to draw on 
common social understanding to engage in argument whilst differing in individual opinion surrounding matters of public controversy (Billig, 1993, 1996).

As such rhetoric pinpoints argument as definitive of attitudes, without which they would cease to exist, in a world only inhabited by truths. Shotter's (1993) observation that truth is 'made' rather than 'found' is insightful. Rhetorical study stresses the need to account for argument where: 'Disagreement is praised as the root of thought' (Billig, 1996, p. 1). Disagreement need not imply a destructive state of affairs, but alternatively rhetoric underlines its importance as a core feature of all conversational acts, in the constructive negotiation of reality (Billig, 1996). As a trans-historical fact the occurrence of rhetorical discourse is seen as a creative force that constructs psychological reality in terms of specific 'language games' commonly understood from those within the same linguistic community (Billig, 1997). Therefore social discourse may be said to possess a history, embedded in a unique context, which gives rise to distinctive thinking and actual behavioural outcomes (Gill \& Whedbee, 1997). From this; as in the material-discursive perspective; thinking, speech and action are closely related activities whose differences should not be overstated (Billig, 1997). Thus in opposition to the guiding Cartesian maxim of modernist philosophy 'I think therefore I am', thinking is not seen as an act undertaken by the isolated individual, but rather exists in the social sphere where even individual '... thought is the silent conversation of the soul with itself ...' (Billig, 1991, p. 49).

Social representations theory has also spurred much controversy in recent social psychological debate in its challenge to many of the dominant practices within the field (Billig, 1988, 1993). Likewise it offers crucial insight into the relationship between social processes and individual functioning that are otherwise ill considered (McKinlay, Potter, \& Wetherell, 1993). In short the theory attempts to locate each individual's psychological functioning in terms of his or her location in a larger socio-cultural milieu.

It is suggested that psychological experience is moulded through the individual's contextual membership within a social group who share a common understanding of the surrounding world (Augoustinos \& Walker, 1995). That is to say social representations are argued to encapsulate individual understanding of socially negotiated reality, seen as a cognitive phenomenon providing meaning and structure to the experiential world, and as such facilitating thought and group communication (Augoustinos \& Walker, 1995; Foster \& Nel, 1991). Farr (1993) stresses the flexibility and fluidity with which they are collectively 'bargained' in society, highlighting their utility as a means to explore contextual differences in group conceptual understanding.

Centrally the theory provides a way in which to understand the actual processes involved in the collective debate of social reality. In this regard social representations are seen to attach meaning to everyday events and objects that the individual encounters, normalizing particular ways of understanding these phenomena. This is supposedly achieved through two distinct processes (namely anchoring and objectification) whose central objective concerns making the 'unfamiliar familiar' (Augoustinos \& Walker, 1995; Billig, 1993; Foster \& Nel, 1991).

It is apparent that any investigation operating from within the ambit of social representations would profit from the insights of rhetoric. The theory largely disregards the dialogic nature of thinking, exploring the form of thought, as opposed than its contextual produc- 
This is the peer reviewed version of the following article: Luyt, Russell (2003) Rhetorical representations of masculinities in South Africa: Moving towards a material-discursive understanding of men. Journal of Community \& Applied Social Psychology, 13 (1). pp. 46-69. ISSN 1052-9284 (Print), 1099-1298 (Online) (doi:10.1002/casp.706), which has been published in final form at http://doi.org/10.1002/casp.706. This article may be used for non-commercial purposes in accordance with Wiley Terms and Conditions for Self-Archiving.

tion. In this sense rhetoric offers a means to explore how the 'thinking society' thinks, rather than what it thinks.

Both approaches draw on critical theory for their justification and unite in their criticism of individualist perspectives. They reject one-dimensional cognitive explanation that 
views human thought as a function of internal rules, in which predetermined schemata or 'cognitive templates', guide individual thinking within a 'social void'. These approaches preferably choose to suggest the socially interactive and interpretive nature of the surrounding world in which social communication elbows room for conceptual challenge and change (Billig, 1993).

Despite social representations criticism of mainstream cognitive psychology, the theory ultimately advocates their existence as cognitive systems, these guided by their own rules of logic and language (Billig, 1988). McKinlay et al. (1993) note that the theory traditionally inhabits a constructivist position, indicating that no objective reality exists outside of human perception, and as such only through the cognitive construction of meaning does the surrounding world hold any form. Nevertheless a fundamental difference does remain between social representations and cognitivism. Whereas cognitivism locates thinking as a process of individual functioning, social representations stresses its location within the active social group, to which the individual contributes (Billig, 1988). In this sense social representations attempts to incorporate a social dimension hither unto ignored by cognitivism. Unsurprisingly, however, the theory continues to undergo rigorous criticism. It is argued that although it attempts to consider the social, its implicit cognitivism continues to lead to reductionist deficiency, in which individual processes are still afforded primacy over social dynamics.

Augoustinos and Walker (1995) propose that the problems associated with viewing social representations as cognitive objects may be overcome through their alternative conceptualization as discursive products. It is noted that verbal conversation acts as the central axis around which communication, and as such negotiation, of collective understanding takes place (Billig, 1993; McKinlay et al., 1993). In this regard rhetoric claims that traditional psychology has ignored the dialogic nature of thinking, exploring the form of response, rather than its contextual negotiation.

Similarly Billig $(1988,1993)$ suggests it is the dialogic character of thinking that is missing in an account of social representations. Viewed from a rhetorical approach, social representations emerge as arguments, rather than cognitive truths. Every representation harbours the 'negative' potential for counter-argument in which dominant representations may be either accepted or rejected. This destabilizes the theory's problematic assumption that social representations find homogenous reproduction in society. Rhetoric usefully reminds us that the content of 'modern commonsense' contains both conflicting and inconsistent themes. In addition it highlights that this inconsistency appears within groups, rather than predominantly between them, as social representations tends to suggest (Billig, 1993).

However opponents protest that this conceptualization, depicting representations as mere 'linguistic repertoires', disregards that collective thought may exist long before social concepts are verbalized. Nevertheless this article firmly supports considering the merits of a constructionist perspective. This may prove fruitful in the investigation of social representations, in which reality is seen to exist 'between' individuals, continually undergoing transformation during the process of language production and reproduction (Gergen \& Gergen, 1991). Moreover it accounts to a better extent for conflict and contestation over meaning. In the future it may well be beneficial to extend the debate to one in which both the material and discursive elements of social representations are actively theorized. 
This is the peer reviewed version of the following article: Luyt, Russell (2003) Rhetorical representations of masculinities in South Africa: Moving towards a material-discursive understanding of men. Journal of Community \& Applied Social Psychology, 13 (1). pp. 46-69. ISSN 1052-9284 (Print), 1099-1298 (Online) (doi:10.1002/casp.706), which has been published in final form at http://doi.org/10.1002/casp.706. This article may be used for non-commercial purposes in accordance with Wiley Terms and Conditions for Self-Archiving.

It is the complexities surrounding rhetorical representations of masculinity in South Africa that this study attempts to highlight. Qualitative data provides a rich social text that 
suitably may be understood as 'a performance transcribed'. This facilitates understanding into (a) how men in society reproduce knowledge concerning themselves through dialogical thought, and (b) illustrates how gender is acted-out within the constraints of the contextual body. Interest in metaphorical language served to guide analysis throughout this venture. Metaphor usefully provides a means with which to explore the way in which society incorporates understanding of unfamiliar concepts in terms of existing explanatory referents (Gill \& Whedbee, 1997; Liakopoulos, 2000).

An appreciation of representational contradiction may be accomplished through the recognition that metaphors act as persuasive tools, which may be used in substantiating the 'truth' of any argument (Lakoff \& Johnson, 1980; Leach, 2000), underlining their rhetorical utility for both dominant and subordinate conceptualizations. In gender terms: not only do hegemonic masculinities make use of familiar metaphor, but so too do subordinate 'Others', in which each subsumes available understanding in aid of justification and criticism.

Thus metaphor may be seen to aid conceptualization of reality in a culturally relevant manner, in which 'understanding and experiencing one kind of thing in terms of another' (Lakoff \& Johnson, 1980, p. 5) serves to maintain particular truths, whilst suppressing others. Lakoff and Johnson (1980) note that although these 'hegemonic metaphors' are not easily open to change, new 'creative metaphors' may emerge to challenge the old, in part through argument. This confirms the advantage of metaphoric exploration in the analysis of rhetorical representations of hegemonic masculinity. That is to say whilst hegemonic understanding is seen to define the conceptual landscape it fails to prevent other voices from challenging its normative definitions.

\section{Summary}

Through an analysis of rhetorical representations this article seeks to highlight the importance of embracing a material-discursive approach in understanding masculinities. Watson (2000) argues that embodied sociology has largely been theory driven and lacks sufficient empirical focus. Through illustrating the complexity surrounding lived masculinity within South Africa, it is anticipated that the merits of a material-discursive approach will be reinforced, and that the current empirical void may be somewhat ameliorated.

\section{METHOD}

The qualitative data presented in this article was drawn selectively from a larger study seeking to explore contemporary masculine debate within South Africa. Focus group and individual interview methods were employed in order to provide rich discursive material. Although a reflexive account surrounding the co-construction of these masculinities is worth mention, in which issues of 'race' and class surface as particularly salient features within a South African research context, this proves beyond the scope of the current article. Readers are encouraged to contact the author for more detailed information in this regard, and may usefully consult Radley and Billig (1996), who provide constructive debate surrounding this issue. 
This is the peer reviewed version of the following article: Luyt, Russell (2003) Rhetorical representations of masculinities in South Africa: Moving towards a material-discursive understanding of men. Journal of Community \& Applied Social Psychology, 13 (1). pp. 46-69. ISSN 1052-9284 (Print), 1099-1298 (Online) (doi:10.1002/casp.706), which has been published in final form at http://doi.org/10.1002/casp.706. This article may be used for non-commercial purposes in accordance with Wiley Terms and Conditions for Self-Archiving.

Seventy-seven individuals agreed to participate in focus group procedures. Discussion was conducted in one of three languages (Afrikaans, English, or Xhosa); their separate 
inclusion acting as a means by which to ensure cultural diversity in participant understanding. Moreover purposive sampling within the Cape Town metropolitan area along predetermined 'social class' criteria aided attempts to obtain rich participant variety.

Social class has repeatedly been underlined as a core variable in the differential construction of masculinity (Connell, 1993, 1995; Edley \& Wetherell, 1995; Messner, 1997; Morgan, 1992; Pleck, 1995; Pyke, 1996). It is easily operationalized through occupational status and intertwined with many other influential variables that impact upon masculine difference; most conspicuously 'race' (Hooks, 1995; Morrell, 1998; Ratele, 1998). It is significant that the interlocking nature of 'race' and class appears particularly strong in South Africa given its past of institutionalized discrimination (Morrell, 1998, 2001). Nevertheless exploration of masculinity by social class alone neglects one key sphere of masculine experience: that of sexual identity.

Sexuality is also argued to exist as a central axis of masculine diversity (Boyarin, 1997; Brittan, 1989; Connell, 1995; Frank, 1987; Fuss, 1989; Jackson, 1990; Messner, 1997; Weeks, 1990). Accordingly focus groups were additionally conducted with men who saw themselves as sexually 'Other', united in their divergence from normative heterosexuality, but varied in their sexual self-definition. Eight focus groups were undertaken in order to assess participant views in sufficient depth. Table 1 summarizes the characteristics of these focus groups.

Focus group discussion lasted between 1 to $1 \frac{1 / 2}{2}$ hours. Meaningful dialogue was achieved through the aid of researchers proficient in each of the three languages, this to a certain extent, reducing reactive cultural barriers between the researcher and those participating. The author undertook the facilitation of English groups. Two male postgraduate students fluent in either Afrikaans or Xhosa were trained to facilitate the remaining groups.

Discussion took form around a loose interview schedule. Krueger (1994) suggests that whilst this allows a degree of focus, it avoids overly directive facilitation, providing ample room to explore the vagaries of group debate. This proved important in an exercise attempting to generate fresh conceptual understanding surrounding masculinity: both from within a rhetorical framework, in which attitudes are better understood within: ' . . . the unfolding arguments in discussion groups' (Billig, 1993, p. 57), as well as in generating homosocial (all-male) interaction. However the flexibility spawned through this approach sets few focal boundaries, at times rendering comparative analyses between focus groups difficult, particularly those conducted in different languages. As such the loose interview schedule found some standardization across focus groups through the supplementation of

Table 1. Focus group characteristics

\begin{tabular}{llcll}
\hline Focus group & Category & $\begin{array}{l}\text { Group } \\
\text { size }\end{array}$ & $\begin{array}{l}\text { Home } \\
\text { language }\end{array}$ & Sponsor \\
\hline Occupation & & & & \\
2 & Student & 10 & English & University of Cape Town \\
3 & Student & 5 & English & University of Cape Town \\
4 & Unemployed & 11 & Xhosa & Community leadership \\
5 & Unemployed & 10 & Xhosa & Community leadership \\
7 & Unskilled/semi-skilled labour & 11 & Afrikaans & Local industry \\
8 & Lower/mid-level management & 10 & Afrikaans & Local industry
\end{tabular}


This is the peer reviewed version of the following article: Luyt, Russell (2003) Rhetorical representations of masculinities in South Africa: Moving towards a material-discursive understanding of men. Journal of Community \& Applied Social Psychology, 13 (1). pp. 46-69. ISSN 1052-9284 (Print), 1099-1298 (Online) (doi:10.1002/casp.706), which has been published in final form at http://doi.org/10.1002/casp.706 . This article may be used for non-commercial purposes in accordance with Wiley Terms and Conditions for Self-Archiving.

Sexuality

1

6

'Other'

'Other'
$10 \quad$ English

10 Xhosa
Triangle project Triangle project 
numerous pictorial representations of masculinity. These were presented to participants toward the end of each discussion and enabled facilitators to draw attention to issues of interest that might not have hither unto been covered. Pictures were drawn from an assortment of sources, and sought to present a complex pattern of masculine experience, in the hope of provoking debate. It may be argued that they held added advantage as a medium to stimulate discussion, acting as pre-verbal cues to thought, allowing participants to draw on their own rather than the facilitators meaning-frame in explanation of what was seen.

After an initial analysis of this material, in which sexuality emerged as a surprisingly powerful theme throughout, it was felt that additional interviews might be beneficial in delving into the differing construction of masculine sexuality in more detail. Therefore, two individuals were approached via personal referral to participate in individual interviews; their selection largely based on convenience. These interviews were conducted in English with men residing within greater Cape Town. Sexual identity served to direct the choice of each man, the first defining himself as 'homosexual', the second describing himself as 'heterosexual'.

The author conducted individual interviews that each lasted between 1 to $1 \frac{1}{2}$ hours. A loose interview schedule was designed so as to ensure some degree of focus while at the same time encouraging the development of narrative. Research objectives stressed the advantage of this method; considered better attuned to the production of comprehensive conceptual understanding than conventional interviewing approaches, and aiding an account of male embodied experience. An abundance of literature exists that provides a detailed account of the narrative method (e.g. Bal, 1997; Hollway \& Jefferson, 2000; Jovchelovitch \& Bauer, 2000; Punch, 1998).

In both focus group and individual interviews, participants were made aware of their ethical rights, including that discussion would be recorded via the use of audio-visual equipment.

\section{Translation}

Translation should remain a considered undertaking. In particular cross-cultural research raises serious questions concerning, often unexamined, universalist assumptions that suggest perfect correspondence between languages. Critics note that languages seldom mirror each other, either linguistically or semantically, and as such the utility of translated material appears at best questionable (Swartz, 1998). Despite heated debate concerning the benefit of translation, a variety of techniques are argued to exist that enhance its value. It is stressed that researchers should ensure familiarity with the cultural norms and behaviour of the research setting, as well as elicit the co-operation of individuals originating from within the specific cultural context under investigation (Neuman, 1997). In appreciation of the importance of these requirements individuals fluent in both the cultural and linguistic subtleties of each focus group undertook translation.

The procedure of back-translation is argued to offer a means with which to overcome many of the weaknesses inherent in cross-cultural research. It attempts to achieve 'lexicon equivalence'. Here translation seeks to echo both the linguistic and semantic structure of the original material. The process involves the independent translation of data by an indi- 
This is the peer reviewed version of the following article: Luyt, Russell (2003) Rhetorical representations of masculinities in South Africa: Moving towards a material-discursive understanding of men. Journal of Community \& Applied Social Psychology, 13 (1). pp. 46-69. ISSN 1052-9284 (Print), 1099-1298 (Online) (doi:10.1002/casp.706), which has been published in final form at http://doi.org/10.1002/casp.706. This article may be used for non-commercial purposes in accordance with Wiley Terms and Conditions for Self-Archiving.

vidual fluent in the target language. This subsequently undergoes 'back-translation' into its primary form by a person unfamiliar with the original text. This provides two matching language versions of the research material that may be compared to determine their 
similarity, creating a space in which crucial adjustments may be made to the translation, as such facilitating greater linguistic and semantic equivalency between primary and translated texts (Neuman, 1997; Swartz, 1998).

Swartz (1998) highlights the importance of attempting to attain semantic congruence between these texts. In affording similarity in meaning higher status than mere word equivalency, it is stressed that a crude empiricist understanding of language may be avoided. Crucially it is underlined that no translation should be seen to provide faultless equivalency, as languages are never perfectly commensurate (Neuman, 1997; Swartz, 1998).

The technique of back-translation was adopted in this research undertaking in which the importance of semantic equivalency was stressed. Translators strove to achieve meaningful similarity between the original Afrikaans and Xhosa material and subsequent English translations, paying particular attention to the subtleties of spoken language.

\section{DISCUSSION}

Seven key 'hegemonic metaphors' emerged from participant debate. Data analysis relied on an iterative process in which both deductive and inductive logic served to inform their materialization. An existing conceptual model of hegemonic masculinity (Luyt \& Foster, 2001) was utilized as a means with which to 'enter' the data. This model incorporated five core dimensions:

(1) Anti-femininity,

(2) Toughness,

(3) Individualism,

(4) Status,

(5) Homophobia.

Textual analysis metamorphosed this original model, ultimately rendering seven metaphorical themes, which differed substantially (in their depth of description) from the a priori theoretical dimensions:

(1) Masculine control: 'It's basically a conquest thing',

(2) Masculine (un)emotionality: 'Having a lion's heart',

(3) Masculine physicality and toughness: 'The iron man',

(4) Masculine competition: 'It's a matter of war',

(5) Masculine success: 'Flying high',

(6) Masculine (hetero)sexuality: 'The steam engine within',

(7) Masculine responsibility: 'Child-minding the world'.

Although the results of this analysis are presented in a rigid fashion, through the description of core metaphors, this should not be understood to imply their actual existence. Rhetorical representation of masculinities is far more complex than may ever be captured in the stasis of writing, where in actuality the discreet definition of each metaphor proves by and large false, as masculine concepts are irreducibly interlinked as well as in constant conceptual flux. Nevertheless, an analysis of this kind proves somewhat useful in demonstrating 'watercolour themes' of lived masculine reality in South Africa. This discussion 
This is the peer reviewed version of the following article: Luyt, Russell (2003) Rhetorical representations of masculinities in South Africa: Moving towards a material-discursive understanding of men. Journal of Community \& Applied Social Psychology, 13 (1). pp. 46-69. ISSN 1052-9284 (Print), 1099-1298 (Online) (doi:10.1002/casp.706), which has been published in final form at http://doi.org/10.1002/casp.706. This article may be used for non-commercial purposes in accordance with Wiley Terms and Conditions for Self-Archiving.

presents three of these metaphors. They illustrate the importance of adopting a materialdiscursive understanding of masculine experience that accounts for the context specific structural and interactional constraints in which the gendered body operates. 
Masculine (un)emotionality: 'To have a lion's heart'

A large body of literature testifies to the fact that masculinity is conventionally understood as encompassing emotional detachment (Buchbinder, 1994; Pleck, 1995; Seidler, 1992, 1994, 1997). Men are metaphorically required to have 'a heart of a lion'. A popular image of the lion, as 'the king of beasts', depicts it as emotionally resolute. Participants suggested that 'real' men, in their stoic emotional fortitude, were similarly impassive:

Int: Does a man cry?

P3: No a man does not cry.

P7: A man only cries on the inside.

Int: Why is it that men cry only on the inside?

P7: A man could die from a heart attack anytime because he never shows his emotions; he just keeps them bottled inside.

Int: What about men who do cry?

P7: No you will never find a man crying, even if he cries you will never hear a sound a sound coming from him. (General laughter) (Unemployment 2: p. 7).

In this extract normative ideology first found immediate and unqualified support from participant 3 (P3) in his assertion that 'a man does not cry'. However it is revealing that the debate progressed so as not to deny that men experienced emotional difficultly, but rather that this was restricted to 'the inside', to the devastating extent that a man 'could die from a heart attack anytime because he never shows his emotions'. Firstly, it is interesting that participants chose to frame their discussion in bodily terms, using language that made direct reference to embodied experience, such as 'the inside' and 'heart attack'. Secondly, this text demonstrates processes of dialogical thinking, which men engaged in throughout group discussions, so as to mutually explore their masculinities. This should be distinguished from argument where divergent positions found open confrontation. Nevertheless in underlining the active suppression of emotion, this disclosure came promisingly close to championing masculinities performative, rather than innate nature. Men were acknowledged to contain an often-unexpressed need to 'cry', as opposed to their conventional representation as emotionless. This statement illustrates what might usefully be called normative reform, where in this case, acknowledgment of internal male emotionality held the seeds for future critical challenge concerning the notion of natural male emotional inability. This differs from outright normative revolution where challenge to dominant conceptualization would find direct confrontation. At times participants were seen to question standards of masculine (un)emotionality in these less ambiguous terms:

P10: ... I see maybe the feminine quality of me shining through in terms of emotion, because I am a very open person. And I'm very directive and very honest, with a lot of sensitivity.

P5: I think that's also got to do with emotional maturity that I was referring to earlier. That again through our upbringing, struggles, trying to find acceptance. You've gone through so much, and accept the issues I'd also like to describe my um... my, my... (inaudible) ... more feminine, or what is perceived as what is perceived as more feminine...

Int: What is perceived as feminine? Emotionality you mentioned... 
This is the peer reviewed version of the following article: Luyt, Russell (2003) Rhetorical representations of masculinities in South Africa: Moving towards a material-discursive understanding of men. Journal of Community \& Applied Social Psychology, 13 (1). pp. 46-69. ISSN 1052-9284 (Print), 1099-1298 (Online) (doi:10.1002/casp.706), which has been published in final form at http://doi.org/10.1002/casp.706. This article may be used for non-commercial purposes in accordance with Wiley Terms and Conditions for Self-Archiving.

P5: Appreciation for beauty. Being... allowing yourself to do that. Allowing yourself ...

P1: Aesthetically sensitive. 
P5: But especially to um, have been a ... empathy for other people's feelings, emotions. Being able to understand other people better.

P3: You can cry... (Sexuality 1: pp. 21-22)

This example, taken from discussion with sexually 'Other' men, exemplifies unguarded argumentative challenge to the conventional ideal of masculine emotional absence. Participants suggested that their own trying life histories had forced them to engage in greater emotional maturity, in many ways 'perceived as more feminine'; this quintessentially contrasting their gender identity from traditional masculinity in their ability to 'cry'. Nevertheless such a comparison alone, between dominant (hetero)sexual and subordinate (other)sexual masculinities understanding surrounding the importance of emotionality, would be overly simplistic and might detrimentally contribute to the reification of such categorical distinctions. It is apparent that disagreement flourished even within subordinate masculine understanding:

P1: There are men who cry and make noise, really.

P2: Is that the case with all men?

P1: No some of them.

P2: But that is not something that is natural because men are not supposed to cry.

Int: Is it a masculine thing that men don't cry?

P1: Yes, men have to be able to endure pain. (Sexuality 2: p. 16)

In this case sexually 'Other' men firmly endorsed normative masculine prescriptions to remain emotionally reserved. Thus, whilst argument may have been ever-present, it is evident that its content found variable support across different socially defined groups. Despite the process of normative justification holding sway in such debate, 'Other' criticism also played a fundamental role in the solidification of dominant understanding, this astutely observed by participants:

P4: Its quite interesting the way everyone keeps saying that emotionality is like feminine.

But if you look at masculinity and masculine, or heterosexual men, the only emotions they're allowed, are that time they fall in love ... and maybe anger. Those are the masculine emotions, and I can't understand why everyone here looks down on feminine emotions which are ... is quite weird ... Um, that, like caring and these kind of things which are called 'feminine' emotions are looked down on... (General talking)

P3: I don't think I understood that either. (Sexuality 1: pp. 44-45)

Billig (1993, 1996, 1997) suggests that the activities of justification and criticism are pivotal in every argument. Both are used as a means with which to influence public debate in support of a particular position. In this case participants perceptively recognized criticism of the feminine as a functional normative masculine attempt to construct an oppositional identity for itself, stressing masculinity's inherent superiority in contrast to femininity where 'things which are called “feminine” emotions are looked down on'; this thereby rigidly defining gender appropriate behaviour. In other words, men in the discussion identified that the expression of emotion is strongly shunned due to it being seen as 'like feminine', alternatively encouraging male emotional detachment and independence as a sign of 'true' masculinity. However such argumentative insight was usually absent in the normative endorsement of male (un)emotionality: 
This is the peer reviewed version of the following article: Luyt, Russell (2003) Rhetorical representations of masculinities in South Africa: Moving towards a material-discursive understanding of men. Journal of Community \& Applied Social Psychology, 13 (1). pp. 46-69. ISSN 1052-9284 (Print), 1099-1298 (Online) (doi:10.1002/casp.706), which has been published in final form at http://doi.org/10.1002/casp.706. This article may be used for non-commercial purposes in accordance with Wiley Terms and Conditions for Self-Archiving.

Int: Do you think that you have lost anything in not being able to discuss things with other guys? 
Participant: Um, no I don't think so. Um, I think I've, I always seem to have had girl friends that I could talk to about... Um, and again it wasn't as if I could never talk to my guy friends about stuff like that, I could but not too, um, could never get too wishy-washy, and they would never get too wishy-washy with me. Um, which um, I think is fine because you know we become more and more attached to our feminine side, I think we could take it too far. (Interview 2: p. 15)

Although admitting, 'I always seem to have had girl friends that I could talk to', the participant in this example reasserts his belief that emotional 'wishy-washy' talk holds inherent dangers in that 'we become more and more attached to our feminine side' and ultimately 'take it too far'. In this case taking it 'too far' refers to losing one's masculine identity through a failure to exercise control over emotional vulnerabilities. Consequently men are said to constantly engage in activities that overtly demonstrate their emotional and physical strength together with their toughness (Pyke, 1996; Wetherell \& Griffin, 1991). In short normative prescriptions demand that men exude toughness whilst always remaining emotionally self-contained (Buchbinder, 1994; Toch, 1998).

\section{Masculine physicality and toughness: 'The iron man'}

Male emotional denial is believed to facilitate an outward focus on the body in an attempt to divert attention from inward subjectivity. As such, the male body provides a particularly powerful material tool through which hegemonic masculinity may be displayed, as well as offering a clear object for normative correction and control (Connell, 1990). In this sense it proves fruitful to understand hegemonic masculinity as 'situated in a certain "political economy" of the body', which notwithstanding challenge and change, is forever 'at issue - the body and its forces, their utility and their docility, their distribution and their submission' (Foucault, 1979, p. 25). This profitably highlights the materiality of masculine experience.

Connell (1990) offers evidence for the way in which hegemonic masculinity may be displayed through the male body, in his discussion of 'Steve', an iron man sports hero. This metaphor likewise characterized the stress participants regularly placed on bodily physicality and toughness in masculine achievement:

Int: What sort of stereotypes would you say those are? I mean what do they reinforce?

Participant: Um, that, um, that you don't show emotion, um, you love sport you know 'till the dying moment, and you have to, and you have to be good at it. Um, and that you should shy-away from arts, culture, and all of that. Um, and, um, you have to be, you have to be physical to sort out something, you know you have to whack the living daylights out of your opponent physically, um, rather than intellectually or verbally. Um, and it's to a certain extent it's a, it's not condoning violence but it's a society I think and a system that churns-out people that do learn that ultimately violence comes in somewhere along the line, you know. (Interview 1: p. 18) 
The participant in this extract emphasizes 'that you have to be physical to sort out something', in which 'you don't show emotion', and in so doing privilege physical toughness above the 'intellectual(ly) or verbal(ly)'. Conveniently this statement provides both sides of the basic hegemonic argument that (a) 'real' men are outwardly physically assertive 
whereas (b) 'Other' men resort to inwardly emotional resources such as language. Nevertheless it is clear that the interviewee opposes this dominant conceptualization, which he sees as creating 'a system that churns-out people that do learn that ultimately violence comes in somewhere', his actual and argumentative opposition remaining firm despite the rewards that normative compliance are seen to offer:

Int: Do you think most girls are looking for a big thick ... (general talking)?

P2: That's why you can't pick up a girl all dressed up on a Saturday night, they're looking for big thick guys.

P4: There's a Diana Ross song that says, 'I Like Muscles', a Diana Ross song...

P7: Ya, 'girls just want...'

P4: And I heard that song when I was younger, and it just got into me, so I thought, well, most girls like muscles, and I wanted to spend time with them, but I thought, well, then I'd have to put a lot of effort in.

P5: Ya, I hear you, I mean why is it that you find that girls always like guys, or why is there that pressure and whatnot, or why is it that girls won't even give the other guys a chance, they always want to go for the guy who're more beefy, because they're obviously more physically developed, you know, they're bigger. (Student 1: p. 41)

In this case participants supported traditional masculine physicality, fostered through their belief that the reward for being 'big thick guys' is sexual achievement, in that 'most girls like muscles'. It would be tempting to suggest that the rejection of this normative standard in the previous extract stemmed from the participant's sexual 'Otherness', rendering possible heterosexual reward that physicality would offer, at best unappealing. However the importance afforded 'iron man status' was not restricted to heterosexual males, but alternately emerged as a definitive masculine ideal across groups, in which the powerful male physique was understood as an attractive object for both male and female desire:

Int: ... what value do you attach to butchness versus ...

$\mathrm{P} 1: \quad$ In the gay community in general?

Int: Ya.

P1: I think that the more butch, the more value, is added to that. The body-beautiful, ya, and the prototype of what that body-beautiful should look like. I mean all these guys running around in the gyms, its crazy. (Sexuality 1: p. 28)

The 'iron man' therefore surfaces as a dominant representation of hegemonic masculinity in which near, although never complete, consensus is reached surrounding its importance. At its extreme, this results in a distinct narcissism (Connell, 1990), in which 'all these guys running around in the gyms' enact ceremonies of reverence toward a body idol. However normative justification for masculine physicality and toughness not only found support in discussion surrounding sexuality, but those embedded in more pragmatic, often class-based arguments concerning appropriate male labour:

P4: These are hard workers ... (points to a picture with 'Black' labourers).

Int: So if you are a man, you should hard manual labour rather than working using a pen the whole time?

P3: There is a saying that goes it is hard being a man. If you keep saying this it your son you are preparing him for the hardships that he will face later in his life. Perhaps he 
This is the peer reviewed version of the following article: Luyt, Russell (2003) Rhetorical representations of masculinities in South Africa: Moving towards a material-discursive understanding of men. Journal of Community \& Applied Social Psychology, 13 (1). pp. 46-69. ISSN 1052-9284 (Print), 1099-1298 (Online) (doi:10.1002/casp.706), which has been published in final form at http://doi.org/10.1002/casp.706. This article may be used for non-commercial purposes in accordance with Wiley Terms and Conditions for Self-Archiving.

could work at the docks and when the hard times come for him, he will remember your words, that it is hard being a man. 
P1: Sorry sorry Int, P5 can you see that these people are struggling? Those people there are White, they are in suits, why is it like this?

P5: Don't start with the politics now.

P1: No I'm just asking.

P5: There are men and then there are lazy, good for nothing men, do you understand? A lazy good for nothing man is a man that can't lift and carry heavy things...

P3: Men differ in the ways they live their lives...

P3: Sometimes a man picks up a spade and starts working in the garden of his home, perhaps he is digging holes to replace the fence. If you are always in a suit you become too indolent to do work like this; you have to hire people to do it for you. There are many things which one can't do wearing a tie.

P1: I agree with him.

P10: In my view a real man is judged on his achievements. He must be a man that if there is a problem, he must get up and solve it, not just sit around doing nothing...

P3: He is just a useless person. We Black people plant and plough our land, you understand? You find that in White people homes there are employees. They are always in ties and don't know how to work with their hands. We don't hire people to do our work. If your wife sees that the fence needs to be fixed she will tell you to do it. If you try to dodge doing the work, you are the flop because your home will be falling apart while you look on. (Unemployment 1: pp. 27-30)

This extract not only emphasizes the dialogical character of 'Black' unemployed men's accounts that jointly seek to explore the meaning of 'real' masculinity, but also affords insight into how concrete material conditions of life contribute towards masculine negotiation; in this instance reinforcing the centrality of masculine toughness and physicality. That is to say these men are reminded of the fact that 'it is hard being a (Black) man' in a deprived socio-economic setting, and as such they remind their sons' that it is important to remain tough, so as to 'prepare (them) for the hardships that (they) will face later in (their) lives'.

Thus a complex amalgamation of 'race' — and class-based masculine identity appears in this example. These 'Black' participants firmly equate 'true' masculinity with physical labour such as 'plant(ing) and plough(ing)', which 'Black people' undertake, in rhetorical criticism of non-physical labour where 'White people' avoid real work and 'are always in a suit'. An abundance of literature testifies to the added importance physicality and toughness hold for working-class masculinities for which alternative avenues of masculine accomplishment remain closed (Connell, 1995; Hagedorn, 1998; Hooks, 1995; Luyt \& Foster, 2001; Pyke, 1996). It is unsurprising within the South African context, where 'race' and class are largely intertwined given its past of institutionalized discrimination (Morrell, 1998, 2001) that masculine definition draws on these meshed social categories:

Int: Ok, here is another picture of someone at the mines. (Points to a picture of a 'White' labourer)

P1: Here he is, I see him.

Int: That's a White man in the mine.

P1: No he is just standing around because he wouldn't be able to stand this.

P5: He wouldn't be able to do it (the work); he is just posing for the picture... 
This is the peer reviewed version of the following article: Luyt, Russell (2003) Rhetorical representations of masculinities in South Africa: Moving towards a material-discursive understanding of men. Journal of Community \& Applied Social Psychology, 13 (1). pp. 46-69. ISSN 1052-9284 (Print), 1099-1298 (Online) (doi:10.1002/casp.706), which has been published in final form at http://doi.org/10.1002/casp.706. This article may be used for non-commercial purposes in accordance with Wiley Terms and Conditions for Self-Archiving.

Int: Let's say we take a White person and we put him there with you, then we take the machine and give it to both of you, are you saying the White man won't be able to use it? 
P1: He would be able to use it.

P5: He'd be able to use it. But when it comes to strength I am stronger.

P1: Yes, he can try to do the work but he could never be as strong as I am. I'm stronger and that's it. A Black man was born to be strong and muscular and a White man was born to come up with plans. (Unemployment 2: pp. 20-21)

Again Black participants affirm a distinction between 'Black' and 'White' men, in their self-implied innate physicality, and as such their ownership of 'real' masculinity. However this dialogue ends by highlighting the defensive impetus behind many such claims to manliness, in the revealing (and painful) 'race'/class comparison that 'a Black man was born to be strong and muscular and a White man was born to come up with plans'. This is not to intimate that emphases on physicality were absent in normative middle-class definitions of masculinity:

Int: Do we all want to look like this? (General talking)

P6: None of us would mind.

P10: Okay, it would be nice to have this body and look like this guy's face. (General talking)

Int: Why wouldn't everyone?

P10: Because you're a man, you can't, you can’t mute, and read you see... (General laughter)

Int: So are you saying that a guy whose like, a physical guy, can't have intelligence at all?

P2: He can have intelligence, but he's not that focused on his brain, he's more focused on his body. (Student 1: pp. 37-38)

In this extract students debate the re-current theme of physicality versus intellect, once more suggesting their mutual exclusivity, in which men are either seen to reflect 'brawn or brain'. Although participants suggest that 'none of us would mind' having 'this body', greater debate materializes concerning the absolute necessity this plays in contributing towards manhood, this perhaps indicative of the larger choice available to middle-class students in the attainment of masculinity due to their privileged material conditions of life:

Int: Is physically big good?

Participant: Um, it helps. Um, it certainly helped the first team rugby players.

Int: In what way?

Participant: Um, mostly I think with the opposite sex, they were obviously attracted to, um, you know the guys bigger, um, has a big body and is a good looking anyway, then he's actually more attractive than someone who isn't. Um, so I think that's an instant help. Um, and I think the bigger men have gained more respect from their peers, instantly, um, you know first impressions and all of that kind of thing that people don't count, and it's true. Um, so there's more respect that goes along with it, ya. (Interview 2: p. 17)

Thus even middle-class participants saw that to be physically developed 'certainly helped', especially in sexual matters of 'attracting the opposite sex', as well as in compe- titive power relations amongst men where it was seen to gain them 'more respect from their 
This is the peer reviewed version of the following article: Luyt, Russell (2003) Rhetorical representations of masculinities in South Africa: Moving towards a material-discursive understanding of men. Journal of Community \& Applied Social Psychology, 13 (1). pp. 46-69. ISSN 1052-9284 (Print), 1099-1298 (Online) (doi:10.1002/casp.706), which has been published in final form at http://doi.org/10.1002/casp.706. This article may be used for non-commercial purposes in accordance with Wiley Terms and Conditions for Self-Archiving.

peers'. The 'iron man' appeared as a powerful hegemonic masculine metaphor across group discussion, dialogue lying less in counter-hegemonic understanding, than in the importance afforded the metaphor in defining normative masculinity across the 
'race'/class divide. Once again it is clear that the body served as a core referent in participant discussion surrounding this metaphor.

\section{Masculine competition: 'It's a matter of war'}

Brittan (1989) notes that a core feature of modern masculinity appears to be that of competition, this particularly related to the requirements of the industrial Capitalist State, and crucial to achievement in this environment. The centrality of competition as an indicator of masculinity is well documented, and is believed to foster aggression and risk taking behaviour in men, who indulge ceaselessly in these acts in order to prove their manliness (Bird, 1996; Buchbinder, 1994; Connell, 1990; Hantover, 1995; Wetherell \& Griffin, 1991). In many instances male competition was described in metaphorical terms as 'a war':

Int: It's a Saturday afternoon, we are all sitting around, we are all standing there at, at, at Newlands, where the Stormers and... Stormers and the...

P4: Bulls ... Bulls ...

Int: Bulls - the Stormers and the Bulls are playing. What, what is now going on with you, with you, you are going now with your buddies or whoever, you go, you are standing, and you are watching the match. How ... what is going on with you?

P4: P9 and I; there's trouble, and we fight each other (P5 gestures between himself and P9). He's a Stormer and I'm a Bull ... (laughter). See, but when the game is finished, we are, are together again. That's how I see it.

Int: Why is it... why is it like that?

P4: I don't know. I come and watch those two teams, over all these years now they are... Those two are enemies of each other... whether they play together or against each other. (Worker 1: p. 15)

This example demonstrates indirect competition between two male friends, each supporting 'enemy' rugby teams, which provided a vicarious medium through which the two men could 'fight each other'. Mangan (1996, p. 140) discusses the link between sport (rugby in particular) and militarism in nineteenth century imperial Britain whereby 'sport became the ultimate metaphor for war'. Male competition is clearly played out on the sports field, if not directly, then indirectly through the 'team as champion' on a battlefield of masculine design. Significantly men did intermittently dismiss the efficacy of such competition:

P11: It's a situation in which we find ourselves, that we have to look out for one another. And that, that makes our, our togetherness, or, or, or our affinity for one another an essence... (inaudible). If we decide to step outside of that, then, then, we create a problem in all directions. We, we are not one type of person that works at sea... (inaudible).

Int: Totally different people.

P11: And we may be... (inaudible)... back to totally different environments, but in, in the, the situation at sea, we're, we're a unit, we have to be, because our common enemy is the sea... (Worker 1: p. 11) 
This is the peer reviewed version of the following article: Luyt, Russell (2003) Rhetorical representations of masculinities in South Africa: Moving towards a material-discursive understanding of men. Journal of Community \& Applied Social Psychology, 13 (1). pp. 46-69. ISSN 1052-9284 (Print), 1099-1298 (Online) (doi:10.1002/casp.706), which has been published in final form at http://doi.org/10.1002/casp.706. This article may be used for non-commercial purposes in accordance with Wiley Terms and Conditions for Self-Archiving.

In this example participants underlined that 'they have to look out for one another', warning that should competition arise, this would 'create a problem in all directions'. At first glance this extract seems to mirror the rhetorical process of particularization 
wherein hegemonic belief (in competition) finds contradiction. Inconsistency appears to reveal the fallacy that stable masculine conceptualization exists, and in so doing frees this concept from its unyielding definition, thereby exposing it to controversy (Billig, 1985, 1993). However although this extract seemed to challenge the importance of competition in masculine definition, the progressive strength of the dialogue dissipates in the face of contextual peculiarities, where competition is only abandoned when these fishermen face a greater 'common enemy' - 'the sea'. That is to say in the absence of such a shared threat, inter-male rivalry once again comes into view, and support for masculine competition is reinforced explicitly once again:

P2: ... I think when people are around like, guys in their class and stuff like that they actively try and make themselves seem better.

Int: What kinds of things might you discuss if you go to a pub or bar, a bunch of friends, five friends?

P3: Sport...

P4: Women.

P3: Chicks.

P2: Chicks. (Student 2: pp. 15-16)

In all discussions men were seen to compete in a large variety of ways in order to 'actively try and make themselves seem better'. 'Sport' clearly offered an arena in which to prove competitive masculinity, however struggle over women and sexual prowess specifically surfaced as a recurrent theme, often displayed in male talk objectifying 'chicks'. Bird (1996) stresses that non-competitive men lose substantial status and are frequently excluded from male group interaction should they choose not to enter into such rivalry. Therefore criticism of the non-competitive 'Other' again served as an argumentative technique, constructing an identity for normative masculinity that stressed its difference from those 'who weren't seen as one of the boys'; this inflexibly defining gender appropriate behaviour:

Int: What kind of consequences would that hold for you, if you weren't seen as one of the boys?

Participant: Um, it could hold consequences in terms of getting work again. Where I work it's important that you get work because of who you know and who you get on with, um, and if you don't get on with management teams in the different companies then you won't get work. Um, so if I was, um, a woman I might not get as much work, or gay, or Black. It's possible, highly unlikely, but... Um, or just not as seen as one of the boys, so it's sometimes important to go out and have a couple of drinks and watch the rugby with the guys, um, so that they know that you're kind of still can relate to them in terms that they're used to. (Interview 2: p. 8)

This participant astutely recognizes the dilemma arising from normative demand. That is to say either men are forced to partake in competitive exercises in which they 'go out and have a couple of drinks and watch the rugby with the guys' so as to ensure they 'can relate to them in terms that they're used to', or face similar ostracism as 'women ... or gay, or Black' persons do in their forcible exclusion from male homosocial competitive interac- 
This is the peer reviewed version of the following article: Luyt, Russell (2003) Rhetorical representations of masculinities in South Africa: Moving towards a material-discursive understanding of men. Journal of Community \& Applied Social Psychology, 13 (1). pp. 46-69. ISSN 1052-9284 (Print), 1099-1298 (Online) (doi:10.1002/casp.706), which has been published in final form at http://doi.org/10.1002/casp.706. This article may be used for non-commercial purposes in accordance with Wiley Terms and Conditions for Self-Archiving.

tion. Again the centrality of the body in determining male experience is obvious. Practicing normative male competitiveness recurrently relies upon real, or imagined physical competence, in work and leisure activities. 


\section{Summary}

An analysis of rhetorical representations provides insight into the interactive and interpretive nature of masculine experience within South Africa. It stresses the dialogic nature of social representations, which are grounded within unique socio-historical contexts, this facilitating understanding into how men in contemporary society reproduced knowledge concerning themselves within ever-changing material circumstances and through shifting discursive practice. The earlier discussion underlines how social categories such as 'race', class and sexuality contribute toward these qualitatively different material-discursive experiences of masculinity among South African men. In so doing the theoretical integration of social representations and rhetoric provides a means with which to overcome the exaggeratedly consensual view of social reality that social representations typically promotes. Consensus, as well as disagreement, surfaced in participant debate concerning 'what it is to be a man'. In short men both defined and experienced their masculinities, in similar and divergent fashions, within and across categorical divides. It is important to note the contextual nature of these findings. The strength of this article lies in its illustration surrounding the complexity of embodied rhetorical representations of masculinity rather than the generalizability of the results. Other local studies, past and future, may (and should) be meta-analysed to determine the degree and content of common masculine experience.

\section{CONCLUSION}

This article has attempted to underline the importance of adopting a material-discursive perspective in the study of masculinities. The discussion substantiates that monolithic depictions of masculinity inadequately represent the array of identities that take subtle shape within South Africa's unique socio-historical milieu. An uneven landscape of social interaction locates each individual in pre-existing, whilst at the same time changing, notions of gender. It is clear that the body provides individuals the means with which to enact appropriate social behaviour, whilst at the same time re-defining the parameters of social reality through rhetorical debate; this however from within the boundaries of current material reality. In particular positioning in terms of 'race', class, culture, age and history contribute to a process in which masculine identity often reflects composite as well as contradictory images of what it is to be a man. Despite the inevitable over-simplification to which such structural analysis is prone, it is nonetheless believed to offer a useful point of entry into the wilderness of societal masculine negotiation, in which social categories often reflect particular lived realities.

Thus, drawing on groups characterized by such categorical differences, exposed the diversity of masculine embodied experience in South Africa. Far from providing a complete account of masculinities, this discussion provides information fertile in its descriptive utility. An analysis of rhetorical representations helped to sketch this diversity. Billig (1996) notes the utility of Bakhtin's original appraisal surrounding the innately conflictual nature of language through reference to co-occurring 'centripetal' and 'centrifugal' forces in dialogue. Far from existing as an objective and stable descriptive tool, conflicting values permeate language, creating an ambiguity crucial for critical thought. This highlights that 
This is the peer reviewed version of the following article: Luyt, Russell (2003) Rhetorical representations of masculinities in South Africa: Moving towards a material-discursive understanding of men. Journal of Community \& Applied Social Psychology, 13 (1). pp. 46-69. ISSN 1052-9284 (Print), 1099-1298 (Online) (doi:10.1002/casp.706), which has been published in final form at http://doi.org/10.1002/casp.706. This article may be used for non-commercial purposes in accordance with Wiley Terms and Conditions for Self-Archiving.

whilst language may draw debaters within the boundaries of common sense understanding, its hazy boundaries simultaneously foster a diaspora of opinion that seeks to test the very conceptual borders it erects (Billig, 1988). Similarly hegemonic metaphors clearly 
emerged in participant discussion, these common sense explanations defining the conceptual landscape for ceaseless dialogue, however failing to prevent other voices from challenging their normative definitions.

It was hoped that the deconstruction of masculinity as a monolith might contribute toward the destabilization of simplistic unitary exploration into masculinity. This article proposes that a material-discursive perspective holds added advantage in understanding this field. As has been demonstrated, men do not exist as a homogeneous social group, and undoubtedly experience masculinity in complex and contradictory ways. As has been noted, numerous studies exist that explore issues of embodied masculinity. However more work needs to be done in this regard, particularly in the everyday description of male lived reality, rather than more obvious (although important) explorations into topics such as embodied male experience of health (e.g. Watson, 2000).

Post-modernist thought stresses the non-linear complexity of the social world where ‘universalistic discourses of rationalism' hold no place (Barrett \& Phillips, 1992). Dominant feminist thinking at present appears to converge in its attempt 'to understand and (re)constitute the self, gender, knowledge, social relations, culture', and crucially the body, 'without resorting to linear, teleological, hierarchical, holistic, or binary ways of thinking and being' (Flax, 1990, p. 39). It is this emphasis that should inform current exploration into masculinities.

\section{ACKNOWLEDGEMENTS}

This article draws on research undertaken under the auspices of the Department of Psychology at the University of Cape Town. Research funds were partially made available through the University. Thanks go to Mbulelo Jacobs and Ben Truter for their assistance in facilitation; the Triangle Project and Jeffrey Xaki for their needed 'gatekeeping' support; Marelise van der Merwe and Thabisa Moleshe for their professional assistance in translation; Ines Meyer and Caroline Murray for their administrative help and advice; Jenny Luyt for her unreserved encouragement; Don Foster for his overall supervisory guidance and support; and all the men who agreed to take part in the original study.

\section{REFERENCES}

Augoustinos, M., \& Walker, I. (1995). Social cognition: An integrated introduction. London: Sage Publications.

Bal, M. (1997). Narratology: Introduction to the theory of narrative. Toronto: University of Toronto Press.

Barrett, M., \& Phillips, A. (1992). Introduction. In M. Barrett, \& A. Phillips (Eds.), Destabilizing theory: Contemporary feminist debates (pp. 1-9). Cambridge: Polity Press.

Berndtson, A. (1960). Beauty, embodiment and art. Philosophy, Phenomenology and Research, 21, 50-61.

Billig, M. (1985). Prejudice, categorization and particularization: from a perceptual to a rhetorical approach. European Journal of Social Psychology, 15, 79-103.

Billig, M. (1988). Social representation, objectification and anchoring: a rhetorical analysis. Social Behaviour, 3, 1-16. 
This is the peer reviewed version of the following article: Luyt, Russell (2003) Rhetorical representations of masculinities in South Africa: Moving towards a material-discursive understanding of men. Journal of Community \& Applied Social Psychology, 13 (1). pp. 46-69. ISSN 1052-9284 (Print), 1099-1298 (Online) (doi:10.1002/casp.706), which has been published in final form at http://doi.org/10.1002/casp.706. This article may be used for non-commercial purposes in accordance with Wiley Terms and Conditions for Self-Archiving.

Billig, M. (1991). Ideology and opinions. London: Sage Publications.

Billig, M. (1993). Studying the thinking society. In G. M. Breakwell, \& D. V. Canter (Eds.), Empirical approaches to social representations (pp. 39-62). New York: Oxford University Press. 
Billig, M. (1996). Arguing and thinking: A rhetorical approach to social psychology. Cambridge: Cambridge University Press.

Billig, M. (1997). Discursive, rhetorical, and ideological messages. In C. McGarty, \& S. A. Haslam (Eds.), The message of social psychology (pp. 127-145). Oxford: Blackwell Publishers.

Bird, S. R. (1996). Welcome to the men's club. Gender and Society, 10, 120-132.

Boyarin, D. (1997). Unheroic conduct: The rise of heterosexuality and the invention of the Jewish man. Berkley, CA: University of California Press.

Brittan, A. (1989). Masculinity and power. Oxford: Basil Blackwell.

Buchbinder, D. (1994). Masculinities and power. Victoria: Melbourne University Press.

Burkitt, I. (1999). Bodies of thought: Embodiment, identity and modernity. London: Sage Publications.

Campbell, C. (2001). 'Going underground and going after women': masculinity and HIV transmission amongst Black workers on the mines. In R. Morrell (Ed.), Changing men in southern Africa (pp. 275-286). Pietermaritzburg: University of Natal Press.

Carpenter, M. (2000). Reinforcing the pillars: rethinking gender, social divisions and health. In E. Annandale, \& K. Hunt (Eds.), Gender inequalities in health (pp. 36-63). Buckingham: Open University Press.

Carrigan, T., Connell, B., \& Lee, J. (1987). Toward a new sociology of masculinity. In H. Brod (Ed.), The making of masculinities (pp. 88-100). Boston, MA: Allen and Unwin.

Coleman, W. (1990). Doing masculinity/doing theory. In J. Hearn, \& D. Morgan (Eds.), Men, masculinities \& social theory (pp. 170-199). London: Unwin Hyman.

Connell, R. W. (1987). Gender and power: Society, the person and sexual politics. Stanford, CA: Stanford University Press.

Connell, R. W. (1990). An iron man: the body and some contradictions of hegemonic masculinity. In M. A. Messner, \& D. F. Sabo (Eds.), Sport, men, and the gender order: Critical feminist perspectives (pp. 83-95). Champaign, IL: Human Kinetics Books.

Connell, R. W. (1993). The big picture: masculinities in recent world history. Theory and Society, 22, 597-623.

Connell, R. W. (1995). Masculinities. Cambridge: Polity Press.

Demetriou, D. (2001). Connell's concept of hegemonic masculinity. Theory and Society, 30, 337361.

Edley, N., \& Wetherell, M. (1995). Men in perspective: Practice, power and identity. London: Prentice Hall/Harvester Wheatsheaf.

Farr, R. (1993). Theory and method in the study of social representations. In G. M. Breakwell, \& D. V. Canter (Eds.), Empirical approaches to social representations (pp. 15-38). New York: Oxford University Press.

Flax, J. (1990). Postmodernism and gender relations in feminist theory. In L. J. Nicholson (Ed.), Feminism/postmodernism (pp. 39-62). New York: Routledge.

Foster, D. (1997). Perpetrators of gross violations of human rights. Cape Town: Report made to the Truth and Reconciliation Commission.

Foster, D., \& Nel, E. (1991). Attitudes and related concepts. In D. Foster, \& J. Louw-Potgieter (Eds.), Social psychology in South Africa (pp. 345-391). Johannesburg: Lexicon Publishers.

Foucault, M. (1979). Discipline and punish: The birth of the prison. London: Penguin Books.

Frank, B. (1987). Hegemonic heterosexual masculinity. Studies in Political Economy, 24, 159-170.

Fuss, D. (1989). Essentially speaking: Feminism, nature and difference. London: Routledge.

Gergen, K. J., \& Gergen, M. M. (1991). Towards reflexive methodology. In F. Steier (Ed.), Research and reflexivity (pp. 76-95). London: Sage Publications.

Gill, A. M., \& Whedbee, K. (1997). Rhetoric. In T. A. van Dijk (Ed.), Discourse as structure and process (pp. 156-184). London: Sage Publications.

Hagedorn, J. M. (1998). Frat boys, bossmen, studs, and gentlemen. In L. H. Bowker (Ed.), Masculinities and violence (pp. 152-167). Thousand Oaks, CA: Sage Publications.

Hantover, J. P. (1995). The boy scouts and the validation of masculinity. In M. S. Kimmel, \& M. A. Messner (Eds.), Men's lives (pp. 74-80). Boston, MA: Allyn and Bacon.

Hearn, J., \& Collinson, D. L. (1994). Theorising unities and differences between men and between 
This is the peer reviewed version of the following article: Luyt, Russell (2003) Rhetorical representations of masculinities in South Africa: Moving towards a material-discursive understanding of men. Journal of Community \& Applied Social Psychology, 13 (1). pp. 46-69. ISSN 1052-9284 (Print), 1099-1298 (Online) (doi:10.1002/casp.706), which has been published in final form at http://doi.org/10.1002/casp.706. This article may be used for non-commercial purposes in accordance with Wiley Terms and Conditions for Self-Archiving.

masculinities. In H. Brod, \& M. Kaufman (Eds.), Theorising masculinities (pp. 95-115). Thousand Oaks, CA: Sage Publications. 
Hollway, W., \& Jefferson, T. (2000). Doing qualitative research differently: Free association, narrative and the interview method. London: Sage Publications.

Hooks, B. (1995). Comrades in struggle. In M. S. Kimmel, \& M. A. Messner (Eds.), Men’s lives. Boston, MA: Allyn and Bacon.

Hörschelmann, K. (2001). Audience interpretations of (former) East Germany's representation in the German media. European Urban and Regional Studies, 8, 189-202.

Jackson, D. (1990). Unmasking masculinity: A critical autobiography. London: Unwin Hyman.

Jefferson, T. (2002). Subordinating hegemonic masculinity. Theorectical Criminology, 6, 63-88.

Jovchelovitch, S., \& Bauer, M. (2000). Narrative interviewing. In M. Bauer, \& G. Gaskell (Eds.), Qualitative researching: With text, image and sound (pp. 57-74). London: Sage Publications.

Kehily, M. (2001). Bodies in school. Men and Masculinities, 4, 173-185.

Kim, H. W. (2001). Phenomenology of the body and its implications for humanistic ethics and politics. Human Studies, 24, 69-85.

Krueger, R. A. (1994). Focus groups: A practical guide for applied research. Thousand Oaks, CA: Sage Publications.

Lakoff, G., \& Johnson, M. (1980). Metaphors we live by. Chicago, IL: The University of Chicago Press.

Leach, J. (2000). Rhetorical analysis. In M. Bauer, \& G. Gaskell (Eds.), Qualitative researching: With text, image and sound (pp. 207-226). London: Sage Publications.

Liakopoulos, M. (2000). Argumentation analysis. In M. Bauer, \& G. Gaskell (Eds.), Qualitative researching: With text, image and sound (pp. 152-171). London: Sage Publications.

Luyt, R., \& Foster, D. (2001). Hegemonic masculine conceptualisation in gang culture. South African Journal of Psychology, 31, 1-11.

Mangan, J. A. (1996). Games field and battlefield: a romantic alliance in verse and the creation of militaristic masculinity. In J. Nauright, \& T. J. L. Chandler (Eds.), Making men: Rugby and masculine identity (pp. 140-157). London: Frank Cass.

Mangan, J. A. (1999). Global facism and the male body. International Journal of the History of Sport, 16, 1-26.

McKinlay, A., Potter, J., \& Wetherell, M. (1993). Discourse analysis and social representations. In G. M. Breakwell, \& D. V. Canter (Eds.), Empirical approaches to social representations (pp. 134156). New York: Oxford University Press.

Messerschmidt, J. W. (1999). Making bodies matter. Theoretical Criminology, 3, 197-220.

Messner, M. A. (1997). Politics of masculinities: Men in movements. Thousand Oaks, CA: Sage Publications.

Morgan, D. H. J. (1992). Discovering men. London: Routledge.

Morrell, R. (1998). Of boys and men. Journal of Southern African Studies, 24, 605-630.

Morrell, R. (2001). The times of change: men and masculinity in South Africa. In R. Morrell (Ed.), Changing men in Southern Africa (pp. 3-37). Pietermaritzburg: University of Natal Press.

Nettleton, S. (2000). The sociology of health and illness. Oxford: Polity Press.

Neuman, W. L. (1997). Social research methods: Qualitative and quantitative approaches. Boston, MA: Allyn and Bacon.

Pleck, J. H. (1995). Men's power with women, other men, and society: a men's movement analysis. In M. S. Kimmel, \& M. A. Messner (Eds.), Men's lives (pp. 5-12). Boston, MA: Allyn and Bacon.

Punch, K. F. (1998). Introduction to social research: Quantitative and qualitative approaches. London: Sage Publications.

Pyke, K. D. (1996). Class-based masculinities: the interdependence of gender, class, and interpersonal power. Gender and Society, 10, 527-549.

Radley, A. (1997). What role does the body have in illness? In L. Yardley (Ed.), Material discourses of health and illness (pp. 50-67). Routledge: London.

Radley, A., \& Billig, M. (1996). Accounts of health and illness: dilemmas and representations. Sociology of Health and Illness, 2, 220-240.

Ratele, K. (1998). The end of the black man. Agenda, 37, 60-64.

Ray, K., \& Shaw, R. (1987). The structure of spirit embodiment in Nsukka Igbo masquerading traditions. Anthropos, 82, 655-660.

Roberts, C. (2002). A matter of embodied fact: sex hormones and the history of bodies. Feminist Theory, 3, 7-26. 
This is the peer reviewed version of the following article: Luyt, Russell (2003) Rhetorical representations of masculinities in South Africa: Moving towards a material-discursive understanding of men. Journal of Community \& Applied Social Psychology, 13 (1). pp. 46-69. ISSN 1052-9284 (Print), 1099-1298 (Online) (doi:10.1002/casp.706), which has been published in final form at http://doi.org/10.1002/casp.706. This article may be used for non-commercial purposes in accordance with Wiley Terms and Conditions for Self-Archiving.

Shotter, J. (1993). Cultural politics of everyday life. Buckingham: Open University Press. 
Sparks, A. C., \& Smith, B. (2002). Sport, spinal cord injury, embodied masculinities, and the dilemmas of narrative identity. Men and Masculinities, 4, 258-285.

Speer, S. A. (2001). Reconsidering the concept of hegemonic masculinity. Feminism and Psychology, 11, 107-135.

Seidler, V. J. (1992). Rejection, vulnerability, and friendships. In P. M. Nardi (Ed.), Men’s Friendships (pp. 15-33). Newbury Park, CA: Sage.

Seidler, V. J. (1994). Unreasonable men: Masculinity and social theory. London: Routledge. Seidler, V. J. (1997).

Man enough: Embodying masculinities. London: Sage Publications.

Swartz, L. (1998). Culture and mental health: A southern African view. Cape Town: Oxford University Press.

Szwed, J. F. (1975). Race and the embodiment of culture. Ethnicity, 2, 19-33.

Taylor, J. L. (2001). Embodiment, nation, and religio-politics in Thailand. South East Asia Research, 9, 129-148.

Thapan, M. (1997). Introduction: gender and embodiment in everyday life. In M. Thapan (Ed.), Embodiment: Essays on gender and identity (pp. 1-29). Delhi: Oxford University Press.

Toch, H. (1998). Hypermasculinity and prison violence. In L. H. Bowker (Ed.), Masculinities and violence (pp. 168178). Thousand Oaks, CA: Sage Publications.

Watson, J. (2000). Male bodies: Health, culture and identity. Buckingham: Open University Press.

Weeks, J. (1990). Sexuality. London: Routledge.

West, C., \& Zimmerman, D. H. (1991). Doing gender. In J. Lorber, \& S. A. Farrell (Eds.), The social construction of gender (pp. 13-37). Thousand Oaks, CA: Sage Publications.

Wetherell, M., \& Edley, N. (1999). Negotiating hegemonic masculinity. Feminism and Psychology, 9, 335-356.

Wetherell, M., \& Griffin, C. (1991). Feminist psychology and the study of men and masculinity. Part I: assumptions and perspectives. Feminism and Psychology, 1, 361-391.

Whitehead, S. (1999). Hegemonic masculinity revisited. Gender, Work and Organization, 6, 58-62. Williams, S. J., \& Bendelow, G. A. (1998). The lived body. New York: Routledge.

Yardley, L. (1997). Introducing material-discursive approaches to health and illness. In L. Yardley (Ed.), Material discourses of health and illness (pp. 1-24). London: Routledge. 